\title{
CLINICAL STUDY ON PATIENTS WITH GROSSLY ELEVATED ERYTHROCYTE SEDIMENTATION RATE
}

\author{
MD. ZAHIRUL HAQUE ${ }^{1}$, SAKI MD. JAKIUL ALAM ${ }^{2}$, MESBAHUDDIN NOMAN $^{3}$, MA AZHAR $^{4}$
}

\begin{abstract}
:
This study was done in medicine indoor department of Rajshahi Medical College Hospital from January 2004 to March 2004. Consecutive 100 patients, who were advised to test the ESR by their physicians for their complaints and found to have an ESR, equal to or more than $100 \mathrm{~mm}$ in $1^{\text {st }}$ hour, were included in this study. Among 100 patients 56 were male and 44 were female. All of them were classified in five age groups. They were also categorized according to their monthly income and occupation. Fever, generalized weakness, weight loss, pallor, pain, body ache were the common presenting complaints. Haematological disorder appeared to be most common cause (41\%) of marked ESR elevation; followed by infectious diseases (36\%) and connective tissue disorders (17\%). Among the all patients 30\% cases were haematological malignancies (i.e. acute myeloblastic and lymphoblastic leukaemia, lymphomas, multiple myeloma). In 4\% cases the cause could not be elicited.
\end{abstract}

\section{Introduction:}

Erythrocyte sedimentation rate (ESR) is a timehonoured, simple and inexpensive test. Raised ESR may be due to numerous aetiologies ranging from minor curable disease to killer disease like cancer. But grossly elevated ESR (equal to or more than $100 \mathrm{~mm}$ in $1^{\text {st }}$ hour) is an alarming situation and needs prompt diagnosis and treatment. The aetiologies of high ESR are difficult to find out and produce considerable diagnostic dilemma to the physician all over the world.

A good number study done in different part of the world on patients with grossly elevated erythrocyte sedimentation rate to find out the aetiologies are available. But unfortunately in Bangladesh no such study has been done to see the prevalence and to find out the common causes of markedly elevated ESR. The aetiologies of high ESR may be different in this region from those of the other countries. Such as Kalaazar is prevalent in this part of the country, and a study done in Rajshahi Medical College Hospital showed that more than $36 \%$ of Kala-azar patient present with an ESR equal to or more than $100 \mathrm{~mm}$ in $1^{\text {st }}$ hour. ${ }^{1-2}$ This study was carried out in Rajshahi Medical College Hospital to find out the common aetiologies of grossly elevated ESR and to assess the predictive value for an identifiable cause of marked ESR elevation.

\section{Materials and Methods:}

This was a prospective study which was carried out in medical indoor of Rajshahi Medical College Hospital from January 2004 to March 2004. Consecutive 100 patients, who were advised to test the ESR by their physicians for their complaints and found to have an ESR, equal to or more than $100 \mathrm{~mm}$ in $1^{\text {st }}$ hour, were included in this study. Out of 100 patients 56 were male and 44 were female. Patients were divided into five age groups having age range of less than 20 years, 20 to 30 years, 30 to 45 years, 45 to 65 years and more than 65 years respectively. The Westergren method of determining the ESR was used without correction for the haemoglobin value.

Detailed history, thorough clinical examinations were performed to elicit the cause. Total and differential count of WBC, Haemoglobin percentage, Urine R/M/ $\mathrm{E}, \mathrm{X}$-ray chest $\mathrm{P} / \mathrm{A}$ view were done in all cases. Other investigations like Comment on peripheral blood film, Bone marrow study, Splenic aspirate study for LD bodies, Widal test, Tuberculin test, Ultrasonography, X-ray skull and dorso-lumber spine, Lymph node biopsy, FNAC, ANF, RA test, Pleural, Ascitic and Cerebrospinal fluid study were done in special cases.

All patients were analyzed with male-female distinction along with age group distribution, socioeconomic condition, occupation, clinical

1. Clinical Pathologist (Attached to Medicine Unit - White), Dhaka Medical College Hospital, Dhaka

2. Clinical Pathologist (Attached to Medicine Unit - Blue), Dhaka Medical College Hospital, Dhaka

3. Registrar, Department of Nephrology, Dhaka Medical College Hospital, Dhaka

4. Professor \& Head, Department of Medicine, Sir Salimullah Medical College, Dhaka 
presentation and possible diagnosis by using other investigations. The data were analyzed by SPSS version 10 .

\section{Results:}

Table I shows that among total 100 patients majority were male (56\%) and male to female ratio was 1.27:1.

Table: 1

Sex Distributions of the patients

\begin{tabular}{lc}
\hline Sex & Number \\
\hline Male & 56 \\
Female & 44 \\
\hline
\end{tabular}

Table: II shows that majority of the male patients (27\%) were within 31 - 45 age group and most of the female patients (36\%) were within 21 - 30 age group.

Table-II

Age Distribution of the patients

\begin{tabular}{lcc}
\hline Age group & \multicolumn{2}{c}{ Number of Patients } \\
& Male & Female \\
\hline$<20$ & 8 & 12 \\
$20-30$ & 10 & 16 \\
$30-45$ & 15 & 6 \\
$45-65$ & 13 & 8 \\
$>65$ & 10 & 2 \\
\hline
\end{tabular}

Table III and Table IV shows that most of the patients of this study are farmer (45\%) by profession and were of lower socioeconomic class (58\%).

Table-III

Socioeconomic conditions of the patients

\begin{tabular}{lc}
\hline Monthly income & Number of Patients (\%) \\
\hline$<3,000 \mathrm{Tk}$ & 58 \\
$3,000-10,000 \mathrm{Tk}$ & 33 \\
$>10,000 \mathrm{Tk}$. & 9 \\
\hline
\end{tabular}

Table V shows that fever ( $46 \%$ male \& $43 \%$ female), generalized weakness (44\% male \& $40 \%$ female), weight loss ( $24 \%$ male \& $14 \%$ female), pallor $(40 \%$ male \& $24 \%$ female), pain ( $28 \%$ male \& $18 \%$ female), body ache ( $14 \%$ male \& $16 \%$ female) were the common presenting complaints.
Table-IV

Occupations of the patients

\begin{tabular}{lcc}
\hline Occupation & Male (\%) & Female (\%) \\
\hline Farmer & 45 & - \\
Labourer & 3 & 2 \\
Service & 9 & 4 \\
Business & 20 & - \\
Student & 16 & 23 \\
Housewife & - & 64 \\
Unemployed & 2 & - \\
Other & 5 & 7 \\
\hline
\end{tabular}

Table-V

Common presenting complaints of the patients

\begin{tabular}{lcc}
\hline Presenting complaint & \multicolumn{2}{c}{ Number of Patients } \\
\cline { 2 - 3 } & Male (\%) & Female (\%) \\
\hline Fever & 46 & 43 \\
Generalized weakness & 44 & 40 \\
Significant weight loss & 26 & 14 \\
Pallor & 40 & 24 \\
Cough & 20 & 14 \\
Haemoptysis & 0 & 0 \\
Pain & 28 & 18 \\
Lump on the abdomen & 8 & 0 \\
Headache & 12 & 12 \\
Bleeding manifestation & 8 & 10 \\
Alteration of bowel habit & 4 & 2 \\
Body ache & 14 & 16 \\
Night sweat & 10 & 2 \\
Morning stiffness & 2 & 10 \\
Pigmentation & 2 & 2 \\
\hline
\end{tabular}

Table VI shows that haematological disorder appeared to be most common cause (41\%) of marked ESR elevation; followed by infectious diseases (36\%) and connective tissue disorders (17\%). In $4 \%$ cases the cause could not be elicited. 
Table-VI

Diagnoses of 100 patients with ESR e"100 $\mathrm{mm}$ in $1^{\text {st }}$ hour

\begin{tabular}{|c|c|c|}
\hline Diagnoses & Male & Female \\
\hline \multicolumn{3}{|l|}{ Haematological Disorders (total 41): } \\
\hline Acute myeloblastic leukaemia & 5 & 7 \\
\hline Acute lymphoblastic leukaemia & 3 & 2 \\
\hline Aplastic anaemia & 5 & 2 \\
\hline Lymphoma (Hodgkin's/Non-Hodgkin's) & 5 & 2 \\
\hline Multiple myeloma & 6 & 0 \\
\hline Immune haemolytic anaemia & 2 & 1 \\
\hline Myelodysplastic syndrome & 1 & 0 \\
\hline \multicolumn{3}{|l|}{ Infections (total 36): } \\
\hline Pulmonary tuberculosis & 5 & 3 \\
\hline Extar-pulmonary tuberculosis & 4 & 4 \\
\hline Kala-azar & 5 & 3 \\
\hline Enteric fever & 1 & 1 \\
\hline Liver abscess & 2 & 1 \\
\hline Septic arthritis & 1 & 1 \\
\hline Fileriasis & 0 & 1 \\
\hline Bacterial meningitis & 1 & 1 \\
\hline Cerebral malaria & 1 & 0 \\
\hline Septicaemia & 0 & 1 \\
\hline \multicolumn{3}{|l|}{ Connective tissue diseases (total 17): } \\
\hline Rheumatoid arthritis & 3 & 10 \\
\hline SLE & 0 & 2 \\
\hline Rheumatic fever & 1 & 1 \\
\hline Chronic liver disease(2): & 2 & 0 \\
\hline No Diagnosis (4): & 3 & 1 \\
\hline
\end{tabular}

\section{Discussion:}

Erythrocyte sedimentation rate (ESR) measures the rate of sedimentation of RBCs in anti-coagulated blood over one hour. It is a non-specific indicator of diseases. Though the usefulness of ESR has decreased as new method of evaluating diseases have been developed, it is still useful as "sickness index" in persons who have non-specific changes in health status and a moderate probability of underlying disease. ${ }^{3}$ An ESR value exceeding $100 \mathrm{~mm} /$ hour has a $90 \%$ predictive value for serious underlying disease, and a minimal number of tests usually reveal the cause. ${ }^{3}$

Grossly elevated ESR ( $\geq 100 \mathrm{~mm}$ in $1^{\text {st }}$ hour) is a common finding all over the world. There are numerous aetiologies of marked ESR elevation. All the aetiologies in our country may not be as same as in other part of the world; there should be some variation. This study was conducted on 100 cases with ESR equal to or more than $100 \mathrm{~mm}$ in $1^{\text {st }}$ hour selected from the medicine department of one of the medical college hospital in northern Bangladesh.

In the present study, majority of the patients were male $(56 \%)$. No other study is available regarding the male: female ratio among the patients with grossly elevated ESR. However, this may be due to the fact that male patients present themselves in hospitals more commonly than female. General attitude of our female toward hospital admission which they tend to avoid may be another reason. 
In this series, majority of the male patients (27\%) were within 31 - 45 age group and most of the female patients (36\%) were within 21 - 30 age group. One of the common cause of marked ESR elevation is connective tissue diseases, which are most prevalent in the young female patients. This may be cause of higher percentage of female patients of younger age group.

Most of the patients of this study had come from rural area (73\%), farmer (45\%) by profession and were of lower socioeconomic class (58\%). Probably, this was not the true reflection of the community. This study was done in a government hospital. Private sector was not included in this study, which serves a large proportion of affluent, urban patients.

In this study, Haematological disorder appears to be most common cause (41\%) of marked ESR elevation; followed by infectious diseases (36\%) and connective tissue disorders (17\%). In $2 \%$ cases the cause is chronic liver disease. In $4 \%$ cases the cause can not be elicited. Among the all patients $30 \%$ cases are haematological malignancies (i.e. acute myeloblastic and lymphoblastic leukaemia, lymphomas, multiple myeloma). There is no other case of malignancy in this study. This result is little bit different from that of the previous other studies. In a study in Zimbabwe infection was the most common cause (46\%), followed by malignancy (25\%), connective tissue disorder (17\%), renal disease (8\%) and liver disease (5\%). ${ }^{4}$ Pneumonia was the most common infection. In our study, we have found tuberculosis (pulmonary \& extra pulmonary) as the most common infection followed by kala-azar. Lluberas-Acosta \& Schumacher showed that most common cause of ESR e" $100 \mathrm{~mm}$ in $1^{\text {st }}$ hour was infection (47\%). ${ }^{5}$ The other diagnosis in that study was malignancy (17\%), rheumatic disease (33\%), renal disease (27\%) and miscellaneous problems (42\%). $66 \%$ patients had more than one diagnosis.

A study done by Fincher \& Page also revealed the most common cause of markedly raised ESR was infection (33\%) with malignant and renal disease each responsible for $17 \%$ and inflammatory disorder for $14 \%$. In $10 \%$ no cause was identified. ${ }^{6}$

It is surprising not to see the infectious disease as the commonest diagnosis in patients with markedly elevated ESR in this study. Infectious disease is more prevalent in a developing country like Bangladesh, and kala-azar, one of the known causes of marked ESR elevation, is endemic in this region. One possible explanation of this result may be the site of this study which was done in medicine unit of Rajshahi Medical College Hospital. It is a tertiary level referral hospital. Most of infections can be diagnosed and treated at primary and secondary level, such as, at union, upazila or district level. Only those with complications or with diagnostic dilemma are being referred to this hospital.

This may also be the possible explanation why haematological disorders are the most prevalent diagnosis among these patients. Haematological diseases are difficult to diagnose and to treat in the upazila and the district level and most of them are referred to this tertiary referral hospital. Moreover, Haemopoitic malignancy cases getting repeatedly admitted for blood transfusion or therapy might have significantly increased their number in this study thereby making infectious diseases as second common cause of marked elevation of ESR.

Renal disorder was found to be an important cause of markedly raised ESR in most of the studies. But here, we do not get any of them. Probably this is due to the separate nephrology unit in Rajshahi Medical College Hospital where all the renal patients are admitted.

Connective tissue diseases are responsible for $17 \%$ cases in this study. This is comparable to the Zimbabwean study (17\%) but reasonably less than some of the European and American studies where infectious diseases are less common and percentage of connective diseases is higher. ${ }^{7}$

No cause can be found in the $4 \%$ of patients in this study. This is less than other studies where it varied from $5 \%{ }^{8}$ to $10 \% .{ }^{9}$ The rate of positive diagnosis is high in our study. This is possibly due to this study which has been done on symptomatic patients admitted in the hospital. Most other studies included both symptomatic and asymptomatic patients.

So, from this study, it can predicted that in a symptomatic patients having ESR equal to or more than $100 \mathrm{~mm}$ in $1^{\text {st }}$ hour, there is a very high possibility (96\%) of having an underlying serious disease. So, all such patients should be searched for a diagnosis to avoid unwanted delay. 


\section{Conclusion:}

Erythrocyte sedimentation rate is a non specific test. But very high elevation of ESR is associated with serious underlying illness in most cases. Haematological disorder is the most common cause. Infectious disease is the next common diagnosis. Connective tissue disease like, rheumatoid arthritis, SLE, rheumatic fever are also common cause of very high ESR, especially in young women patients.

Though this is a tertiary level hospital based study which may not truly reflect the community. All level of practitioners must be aware of this hospital picture. This study may help them in approaching their patients with markedly elevated ESR in a cost effective way, thereby reducing the cost as well as sufferings of the poor patients of this country.

\section{References:}

1. Chowdhury MAJ, Ahasan HAMN, Rafiquddin AKM, Hussain A. Erythrocyte sedimentation rate in Kala-azar. TAJ 1993; 6:29-30.

2., Rahman H, Siddiqui AB. J Bangladesh Coll Physicians Surg 8: 18-28.
3. Bridgend M. The erythrocyte sedimentation rate. Still helpful test when used judiciously. Postgrad Med 1998; 103: 257-62.

4. Stein CM, Xavier R. Extreme elevation of the erythrocyte sedimentation rate in patients admitted to a general medical ward in Harare, Zimbabwe. J Trop Med Hyg 1989; 92: 259-62.

5. Lluberas-Acosta G, Schumacher HRJ. Markedly elevated erythrocyte sedimentation rates: consideration of clinical implications in a hospital population. Br J Clin Pract 1996; 50: 138-142 .

6. Fincher RM. Page MI. Clinical significance of extreme elevation of the erythrocyte sedimentation rate. Arch Int Med; 146: 1581-3.

7. Bedell, Susanna E. Bush, Booker T. Erythrocyte sedimentation Rate: From Folklore to Fact. The American Journal of Medicine 1985; 78: 1001-7.

8. Stevens D, Tallis R, Hollis S. Persistent grossly elevated erythrocyte sedimentation rate in elderly people: one year follow-up of morbidity and mortality. Gerontology 1995; 41:220-6.

9. Brigden M. Clinical utility of the erythrocyte sedimentation rate. American Family Physicians 1999. 